\title{
VARIASI MORFOMETRIK BEBERAPA JENIS LAMUN DI PERAIRAN KELURAHAN TONGKEINA KECAMATAN BUNAKEN
}

\author{
(Morphometric Variation of the Different Types Seagrass in Bunaken Waters, \\ Subdistrict Bunaken, Tongkeina)
}

\author{
Billy T. Wagey ${ }^{1^{*}}$, Webi Sake ${ }^{1}$ \\ ${ }^{1}$ Program Studi IImu Kelautan, Fakultas Perikanan dan IImu Kelautan, Universitas Sam \\ Ratulangi, Manado \\ *e-mail : bwagey@yahoo.com; ORCID NO.0000-0002-7059-8701
}

Research on morphometric variation seagrass communities in the waters of Bunaken, Tongkeina was done on December 18, 2012. The purposes of this study are to collect data and information about community morphometric variation of seagrass beds. Observation of seagrass in the field includes the identification of the types of seagrass, calculate morphometric variation of using image-J and measure oparameter range of light intensity and temperature. The result showed that seagrass ecosystems in Bunaken Tongkeina is belong into the mix type seagrass bed (multispesific bed), with the discovery of four species of seagrass; Halophila ovalis, Thallasia hemprichii, Syringodium Enhalus acoroides and Syringodium isoetifolium. Moreover, it was found that each species has a morphometric variations that could be clasified into the common range species concerned.

Keywords : Morphometric, seagrass, Hobo loggers, Image-J, Tongkeina

Penelitian mengenai variasi morfometrik komunitas padang lamun di perairan kelurahan Tongkeina kecamatan Bunaken tanggal 10-18 Desember 2012. Tujuan penelitian ini untuk mengumpulkan data dan informasi mengenai variasi morfometrik komunitas padang lamun. Pengamatan lamun di lapangan meliputi identifikasi jenis-jenis lamun, menghitung variasi morfometrik masing masing jenis dengan menggunakan image-J dan mengukur oparameter lingkungan terutama intensitas cahaya dan temperatur. Keadaan Ekosistem Padang Lamun di Perairan Kelurahan Tongkeina kecamatan Bunaken tergolong pada tipe campuran (multispesific bed), dengan ditemukannya 4 spesies lamun antara lain Halophila ovalis, Thallasia hemprichii, Enhalus acoroides dan Syringodium isoetifolium. Setiap species memiliki variasi morfometrik yang masih kisaran umum species yang bersangkutan.

Kata kunci : Morfometrik, lamun, Hobo loggers, Image-J,Tongkeina

\section{PENDAHULUAN}

Lamun (seagrass) atau disebut juga ilalang laut, adalah satu-satunya kelompok tumbuhan hidup di perairan laut dangkal hingga pada kedalaman 50 - $60 \mathrm{~m}$, bahkan mencapai $90 \mathrm{~m}$, namun melimpah di daerah pasang surut. Lamun tumbuh subur pada daerah terbuka pasang surut dan perairan pantai atau goba yang dasarnya berupa lumpur, pasir, kerikil dan patahan karang mati dengan kedalaman sampai $4 \mathrm{~m}$. Dalam perairan yang jernih, beberapa jenis lamun bahkan ditemukan tumbuh sampai kedalaman 8 - $15 \mathrm{~m}$ dan $40 \mathrm{~m}$ (Den Hartog, 1970; Nybakken, 1988; Dahuri, 2003 dan Kordi, 2011).

Lamun tumbuh padat membentuk padang, sehingga dikenal sebagai 
padang lamun (seagrass bads). Lamun dapat tumbuh membentuk padang lamun dengan kepadatan mencapai 4.000 tumbuhan per $\mathrm{m}^{2}$ dan mempunyai Biomassa tetap sebesar $2 \mathrm{~kg} / \mathrm{m}^{2}$. Padang lamun dapat membentuk vegetasi tunggal, tersusun atas satu jenis lamun yang tumbuh membentuk padang lebat, sedangkan vegetasi campuran terdiri dari 2-12 jenis lamun yang tumbuh bersama-sama pada satu substrat. Spesies lamun yang biasanya tumbuh dengan vegetasi tunggal adalah Thalassia hemprichii, Enhalus acoroides, Halophila ovalis, Halodule uninervis, Cymodocea serrulata, dan Thalassodendrom ciliatum (Dahuri, 2004, dan Kordi, 2011).

Penelitian pada ekosistem padang lamun dimana banyak terjadi kegiatan atau aktivitas pemanfaatan oleh manusia sangat terbatas. Dengan adanya penelitian ini diharapkan dapat memperoleh gambaran mengenai morfologi dan ekosistem padang lamun di daerah pemanfaatan seperti di kelurahan Tongkeina Kecamatan Bunaken; sehingga dapat dijadikan sebagai informasi awal bagi penelitian selanjutnya yang berhubungan dengan morfometrik lamun di perairan Sulawesi Utara. Didasarkan pada pentingnya keberadaan ekosistem lamun di perairan pantai maka pengetahuan mengenai morfologi lamun perlu dipelajari baik untuk kepentingan ilmiah maupun kepentingan pengetahuan lamun itu sendiri sebagai bahan informasi dengan cara teknik pengukuran morfologi lamun dengan menggunakan image-J. Tujuan dilakukannya penelitian ini, yakni: mengidentifikasi jenis lamun (seagrass) yang ditemukan di wilayah perairan Sulawesi Utara, mengukur variasi morfologi lamun dengan mengunakan software Image-J, mendeskripsikan habitat dan distribusi species dan biota yang berasosiasi pada ekosistem padang lamun, serta mengukur parameter lingkungan seperti; salinitas, dan temperatur, serta intensitas cahaya dengan menggunakan Hobo pendant loggers.

\section{METODE PENELITIAN}

\section{Tempat dan Waktu Penelitian}

Pengumpulan data dilaksanakan di Kelurahan Tongkeina kecamatan Bunaken kota Manado Provinsi Sulawesi Utara pada tanggal 10-18 Desember 2012. Penelitian ini dilaksanakan di Perairan Kelurahan Tongkeina Kecamatan Bunaken Kabupaten Manado dan berlangsung selama 4 bulan. Kegiatan penelitian meliputi pengambilan data di lapangan, pengumpulan sampel dan penanganan sampel. Penanganan sampel dilaksanakan di Laboratorium Biologi Kelautan.

Perairan Desa Tongkeina termasuk dalam kawasan wilayah kecamatan Bunaken (Gambar 2), memiliki luas area padang lamun sekitar 2-5 ha. Dalam praktek kerja lapang ini titik pengamatan dibagi menjadi 2 stasiun yakni Stasiun I pada titik $\left(1^{0} 34^{\prime} 22,70^{\prime \prime}\right.$ LU $-124^{0} 48^{\prime \prime}$ BT), dan Stasiun II (1023'12.9" LU 124032'32.2" BT). Stasiun I dicirikan sebagai daerah di dekat pantai yang banyak dipengaruhi oleh daratan. sedangkan stasiun II adalah wilayah yang mendekati ekosistem terumbu karang dengan asumsi wilayah ini lebih didominasi oleh pengaruh arus laut.

\section{Pengambilan Sampel}

Pengambilan sampel

menggunakan metode jelajah, sampel langsung dikumpulkan, dicuci dengan air laut dan dimasukkan ke dalam kantung plastik sampel. Saat pengambilan sampel dilakukan, posisi diplot dengan menggunakan GPS. Kemudian dengan menggunakan pisau, sampel lamun diambil dan dimasukkan dalam plastik sampel yang sudah diberi label. Untuk 


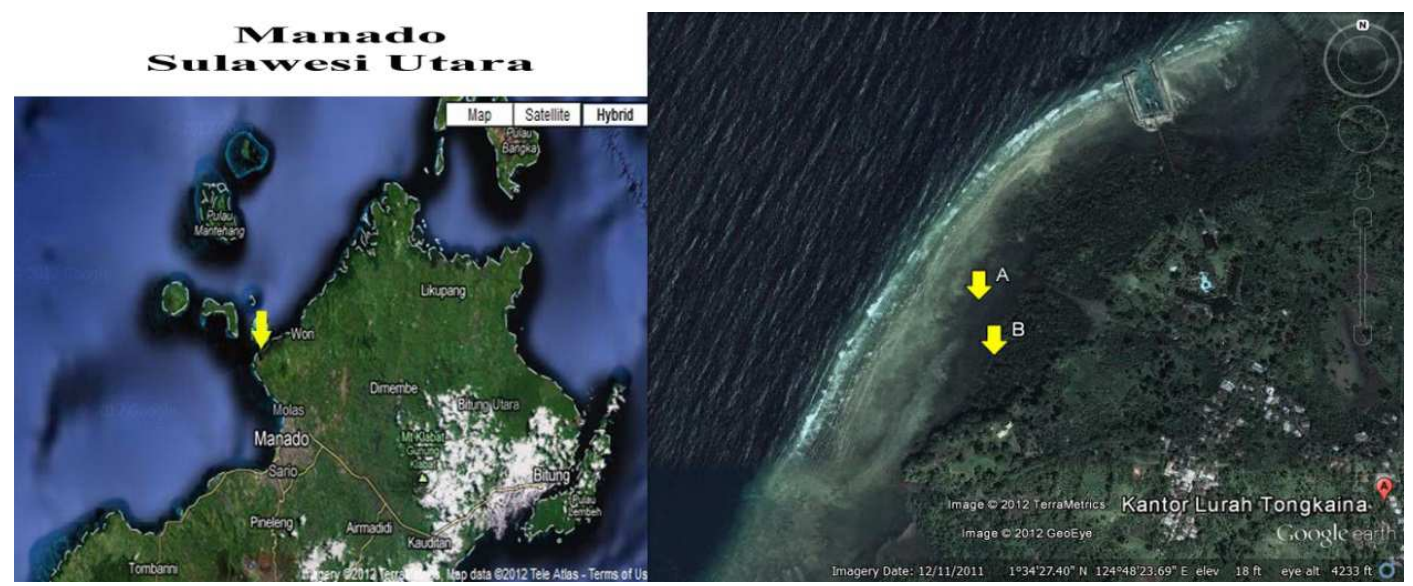

Gambar 1. Peta Lokasi Penelitian

mengukur morfometrik, sampel lamun diambil dari dalam dkuadrat. Sampel yang sudah terkumpul dibawa ke darat, kemudian dibersihkan kotorannya menggunakan air laut dan diberi alkohol $70 \%$ untuk menjaga agar sampel tidak rusak.

Sampel yang telah diperoleh (20 individu per species) kemudian dibawa ke Laboratorium untuk diidentifikasi lebih lanjut. Informasi mengenai temperatur dan intensitas cahaya diperoleh dengan menggunakan alat Hobo Pendant Logger. Alat ini diletakkan pada dua titik di lokasi PKL, pertama di perairan yang dekat pantai dan kedua di perairan yang dekat coral reef. Adapun alat ini diletakkan kurang lebih selama satu hari, kemudian diambil untuk ditransfer data yang telah terekam, Salinitas diukur dengan menggunakan hand refractometer.

\section{Analisis Data}

Analisis data dari sampel yang sudah diperoleh mencakup beberapa tahapan,yaitu :

\section{Identifikasi Sampel}

Sampel lamun yang dibawa ke Laboratorium Biologi Kelautan kemudian difoto satu per satu menggunakan kamera digital. Selanjutnya dengan menggunakan buku identifikasi dari den Hartog (1970); Menez et al, (1983); Calumpong \& Menez (1997); Short \& Cole (2001); Kuo and den Hartog (2001); Waycott et al.,(2004), sampel diidentifikasi kemudian dicatat sampai tingkatan spesies.

\section{Perhitungan Variasi Morfometrik}

Perhitungan variasi morfometrik dari lamun dilakukan secara visual dengan melihat kenampakan luarnya. Pengukuran dilakukan dengan menggunakan software Image_J.. Bagian yang diukur mencakup panjang daun $\left(a_{1}, a_{2} \ldots a_{n}\right)$, lebar daun $\left(b_{1}, b_{2}, \ldots b_{n-}\right.$ ) , panjang batang $\left(c_{1}, c_{2}, \ldots c_{n}\right)$, panjang akar $\left(d_{1}, d_{2}, \ldots d_{n}\right)$ dan panjang rhizoma (e). Dari hasil tersebut dapat dihitung jumlah helaian daun pada setiap tegakan lamun dan rata-rata variasi morfometrik dari masing-masing spesies (Wagey, 2011)

\section{Mengukur Parameter Lingkungan}

Parameter lingkungan yang dihitung mencakup salinitas, temperatur, intensitas cahaya. Alat yang digunakan 
yaitu Hobo Pendant Logger (SeagrassNet), dengan cara meletakkan alat ini pada dua titik berbeda, yaitu di titik dekat pantai Stasiun 1 (shallow) dan yang satu lagi di tempat yang titiknya dekat terumbu karang Stasiun 2 (deep). Alat ini diletakkan untuk mengetahui fluktuasi temperatur dan intensitas cahaya pada lokasi penelitian pada kisaran waktu yang sudah ditentukan

Pengukur salinitas menggunakan hand refraktometer berketelitian $1 \%$, di mana pengukuran ini dilakukan sebanyak tiga kali pada setiap stasiun.

\section{HASIL DAN PEMBAHASAN}

\section{Lamun (Seagrass)}

Berdasarkan penelitian yang dilakukan di perairan Desa Tongkeina Kecamatan Bunaken Kota Manado ditemukan 4 spesies lamun, sehingga wilayah perairan ini dikategorikan ekosistem padang lamun yang bertipe campuran. Setelah diidentifikasi jenis lamun tersebut antara lain Halophila ovalis, Thalassia hemprichii, Enhalus acoroides, Syringodium isoetifolium. Keanekaragaman jenis pada lokasi penelitian ini hampir sama dengan jenis yang terdapat di beberapa perairan di Semenanjung Minahasa, antara lain: perairan Arakan Wawontulap (4 species) perairan Tandurusa (4 spesies), Kema II (3 spesies), Mokupa (4 spesies) dan Sapa (2 spesies). (Peuru, 2005) (Merly 2012). Dari hasil tersebut diatas dapatlah dikatakan bahwa ekosistem padang lamun perairan Tongkeina tergolong pada tipe ekosistem campuran (multyspesific bed).

Berikut ini akan dibahas masing masing spesies berdasarkan karakteristik dan ukuran morfologinya.

\section{a. Halophila ovalis}

Karakteristik dari lamun jenis ini memiliki sepasang daun yang berbentuk oval atau oblong, dengan ujung daun atau apeks bulat. Pada setiap tegakan ditemukan sepasang tunas yang disebut lutsinar, yang terdapat pada pangkal (node) yang terletak diantara batang dan rhizoma. Panjang rhizoma 0,2 - 3,2 cm sedangkan panjang lutsinar ini yaitu berkisar antara 0,2-0,6 cm. Panjang daun yang dimiliki H.ovalis berkisar antara $0,3-2,7 \mathrm{~cm}$ dengan lebar daun $0,5-1,6 \mathrm{~cm}$. Jumlah tulang daun (cross vein) yakni $5-20$. Selain itu $H$. ovalis ini juga memiliki tangkai daun (petiolate) dengan panjang antara $0,1-4,1 \mathrm{~cm}$ dan akar 0,2 - 5,3 cm. Pada Gambar 4 diperlihatkan karakteristik kunci dari spesies $H$. ovalis.

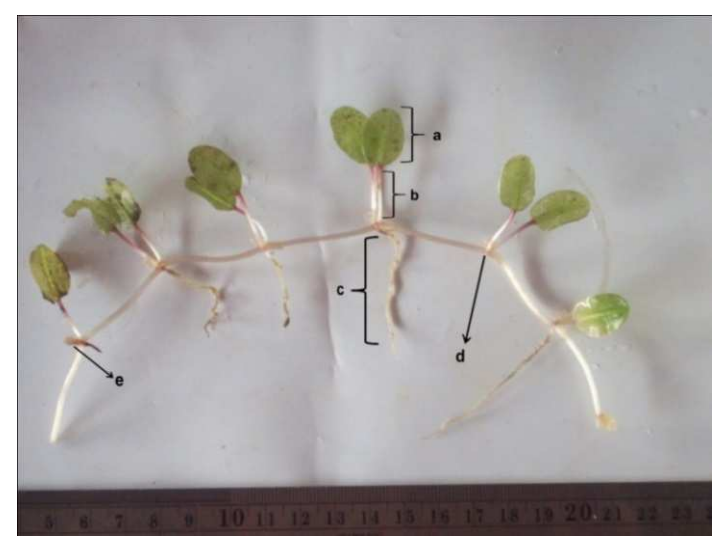

Gambar 2. Halophila ovalis

Ket. : (a) daun, (b) batang, (c) akar, (d) nod dan (e) lutsinar

\section{b. Thalassia hemprichii}

Lamun jenis ini memiliki karakteristik bentuk daun seperti tali (strap-like) yang melengkung, bagian apeks bulat, berwarna hijau gelap dengan jumlah helai dalam satu tegakan yaitu $2-5$ helai. Pada daun juga dilapisi dengan upih yang berwarna putih kecoklatan yang terhubung sampai bagian batang, batang tegak dengan ukuran panjang antara $3,0-8,6 \mathrm{~cm}$. Selain itu panjang daun $T$. hemprichii ini berkisar antara $0,5-15,5 \mathrm{~cm}$ dan lebar $0,3-1,1 \mathrm{~cm}$ 


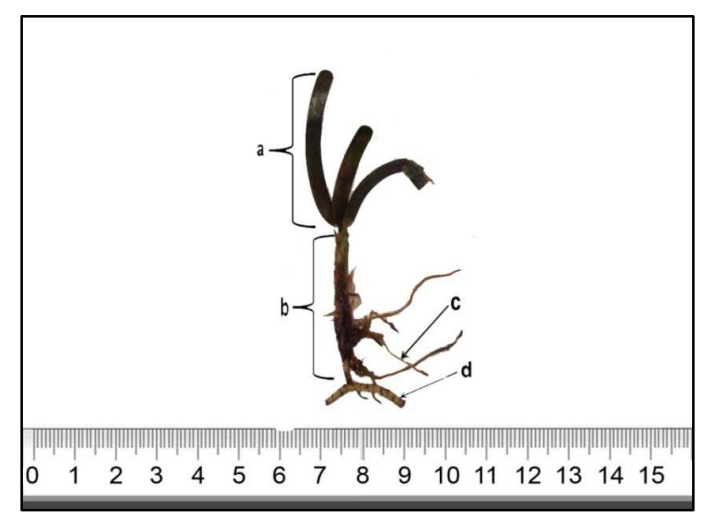

Gambar 3. Thalassia hemprichii Ket. : (a) daun, (b) batang, (c) akar, (d) rhizoma

Rhizoma ukurannya berkisar antara $0,8-6,0 \mathrm{~cm}$, berwarna putih agak merah muda pucat serta terdapat semacam parutan (scars) berwarna hitam. Adapun akar yang tumbuh pada bagian bawah rhizoma ini memiliki panjang bervariasi yakni 0,3 - $15 \mathrm{~cm}$. Lebih jelas lagi ditampilkan seperti pada Gambar 3.

\section{Perbedaan}

spesies

T. hemprichii di perairan Tongkeina dengan beberapa desa di perairan Semenanjung Minahasa yaitu terlihat dari jumlah helaian daun. Dimana T. hemprichii di perairan Tongkeina memiliki $2-5$ helai daun, sedangkan di lokasi lain di Semenanjung Minahasa menurut Peuru (2005), jumlah helaian daun berkisar antara $2-6$ helai. Selain jumlah helaian, ukuran daun baik panjang maupun lebar yang dimiliki oleh spesies T.hemprichii $(0,5-15,5 \mathrm{~cm}$ dan 0,3-1,1 cm) pada lokasi praktek lapang berbeda dengan yang ditemukan di Filipina yaitu $7-40 \mathrm{~cm}$ dan $0,4-1 \mathrm{~cm}$ (Menez, dkk., 1983). Spesies ini jika dilihat sekilas, memiliki kesamaan dengan spesies Cymodocea rotundata. Karakteristik yang membedakan antara $T$. hemprichii dengan $C$. rotundata yakni pada rhizoma dari $T$. hemprichii yang lebih tebal dan terdapat parutan (scars).
Selain itu $C$. rotundata memiliki daun yang lebih tipis dengan lebar daun yang lebih kecil, lebar daun berkisar antara $0,2-0,6 \mathrm{~cm}$, sedangkan panjang daun berkisar antara 0,6 - 19,0 cm dengan jumlah helaian dalam satu tegakan yakni $2-4$ helai. Bagian ujung daun yang berbentuk bulat dan agak tajam. Bagian batang jenis ini memiliki panjang yakni berkisar antara 0,5 $-5,5 \mathrm{~cm}$. Adapun panjang rhizome berkisar antara 0,8 $8,9 \mathrm{~cm}$. Akar yang tumbuh tidak beraturan dan terletak di bawah node memiliki ukuran panjang antara 1,9 $13,6 \mathrm{~cm}$.

\section{c. Enhalus acoroides}

Spesies ini adalah spesies yang paling umum, banyak ditemukan, sangat mudah dikenali dan berukuran lebih besar jika dibandingkan dengan jenis lamun lainnya. Spesies ini ditemukan pada seluruh titik pada stasiun pengamatan. Karakteristik dari lamun jenis ini yaitu memiliki daun yang tebal, bentuk daun memanjang seperti pita (strap-like) dengan apeks berbentuk bulat. Pada Gambar 4 terlihat salah satu spesies lamun yang teridentifikasi sebagai Enhalus acoroides. Spesies ini memiliki 3-5 helai daun dalam satu

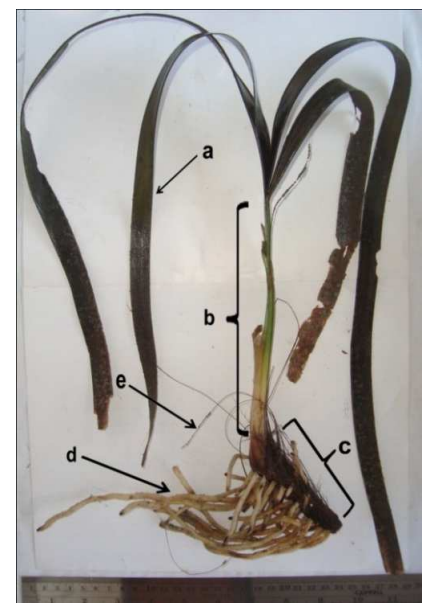

Gambar 4. Enhalus acoroides 
Ket. : (a) daun, (b) batang dan pelepah,

(c) rhizoma, (d) akar, (e) sabut hitam tegakan dengan ukuran panjang daun berkisar antara 2,0 - 54,3 cm dan lebar antara $0,6-1,5 \mathrm{~cm}$. Rhizoma berukuran antara $1-8,3 \mathrm{~cm}$, pada bagian ini juga diselubungi oleh sabut tebal berwarna hitam, selain itu terdapat akar-akar berwarna putih kecoklatan yang berukuran $1-27,7 \mathrm{~cm}$.

\section{d. Syringodium isoetifolium}

Karakteristik dari lamun jenis ini yaitu daunnya berujung runcing, berbentuk silinder berjumlah $1-2$, berukuran panjang antara 0,5-18,0 cm dengan diameter $0,1-0,2 \mathrm{~cm}$. Antara daun dan rhizoma terhubung oleh batang yang agak keras dengan panjang berkisar antara 1,0-5,0 cm. Dari bagian pangkal daun sampai batang diselubungi oleh upih yang berwarna putih kecoklatan. Akar tumbuh di bagian bawah pangkal yaitu antara batang dan rhizoma atau disebut juga node. Panjang rhizoma dan akar berkisar antara 0,4 $9,0 \mathrm{~cm}$ dan $0,8-6,4 \mathrm{~cm}$. Karakteristik dari $S$. isoetifolium ini lebih jelas terlihat pada Gambar 5.

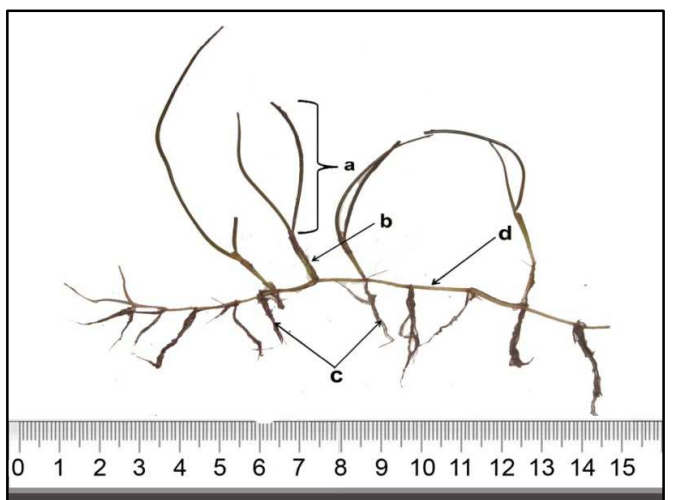

Gambar 5. Syringodium isoetifolium

Ket. : (a) daun, (b) batang, (c) akar, (d) rhizoma

Spesies $S$. isoetifolium memiliki ciri khas bentuk daun yang silinder. Menurut
Kuo \& Hartog (2001) S. isoetifolium memiliki 2 - 3 daun setiap node dan berdiameter $1-2 \mathrm{~mm}$, sehingga spesies ini jelas memiliki kemiripan dengan spesies yang telah diidentifikasi. Selanjutnya Peuru (2005) mengungkapkan panjang daun S.isoetifolium $14-15 \mathrm{~cm}$ dengan diameter $0,08-0,1 \mathrm{~cm}$, hasil ini tidak berbeda jauh dengan hasil pengukuran yang dilakukan pada sampel $S$. isoetifolium di perairan Desa Tongkeina. Sedangkan spesies yang sama yang ditemukan di Filipina panjang daunnya mencapai $25 \mathrm{~cm}$ dengan lebar daun $0,10-0,25 \mathrm{~cm}$ (Menez, dkk., 1983).

Keempat spesies lamun di atas yang telah berhasil diidentifikasi memiliki perbedaan baik dari bentuk maupun ukuran. Adapun bagian yang diukur panjang dan lebarnya antara lain pada bagian daun $(a, b)$, batang(c), akar (d) dan rhizoma (e). Lebih jelas perbedaan morfologi tersebut ditunjukkan pada Tabel 1.

\section{Parameter Lingkungan}

Parameter lingkungan merupakan hal yang penting dalam menunjang keberadaan ekosistem padang lamun termasuk di dalamnya biota yang berasosiasi. Perairan Tongkeina memiliki salinitas antara $30-33 \%$. Selanjutnya untuk pengukuran temperatur dan intensitas cahaya dilakukan dengan menggunakan alat Hobo Pendant logger dari SeagrassNet yang ditempatkan pada satu titik. Hasil pengukuran diperoleh yaitu temperatur berkisar antara 23 - $39{ }^{\circ} \mathrm{C}$ (rata-rata $29{ }^{\circ} \mathrm{C}$ ) dengan intensitas cahaya tertinggi 187,379.0 lux (Gambar 6).

Salah satu faktor yang mempengaruhi temperatur yakni kepadatan dari vegetasi lamun (Koch \& Verduin, 2001). Menurut Nur,2011) temperatur memiliki pengaruh yang sangat besar bagi lamun karena akan 
Tabel 1. Data Hasil Pengukuran Morfometrik Lamun

\begin{tabular}{|c|l|c|c|c|c|c|c|}
\hline No & \multicolumn{1}{|c|}{ Spesies } & $\begin{array}{c}\text { Jumla } \\
\mathbf{h} \text { Helai }\end{array}$ & $\begin{array}{c}\text { Panjang } \\
\text { Daun } \\
\mathbf{( c m})\end{array}$ & $\begin{array}{c}\text { Lebar } \\
\text { Daun } \\
\mathbf{( c m})\end{array}$ & $\begin{array}{c}\text { Pjg. } \\
\text { Batang } \\
\mathbf{( c m})\end{array}$ & $\begin{array}{c}\text { Panjang } \\
\text { Akar } \\
\mathbf{( c m})\end{array}$ & $\begin{array}{c}\text { Rhizom } \\
\mathbf{a}(\mathbf{c m})\end{array}$ \\
\hline 1. & $\begin{array}{l}\text { Thalassia } \\
\text { Hemprichii }\end{array}$ & $2-5$ & $0,5-15,5$ & $0,3-1,1$ & $3,0-8,6$ & $0,3-15,0$ & $0,8-6,0$ \\
\hline 2. & $\begin{array}{l}\text { Halophila } \\
\text { ovalis }\end{array}$ & 2 & $0,3-2,7$ & $0,2-1,6$ & $0,1-4,1$ & $0,2-5,3$ & $0,2-3,2$ \\
\hline 3. & $\begin{array}{l}\text { Syringodium } \\
\text { isoetifolium }\end{array}$ & $1-2$ & $0,5-18,0$ & $0,1-0,2$ & $1,0-5,0$ & $0,8-6,4$ & $0,4-9,0$ \\
\hline 4. & $\begin{array}{l}\text { Enhalus } \\
\text { acoroides }\end{array}$ & $3-5$ & $2,0-54,3$ & $0,6-1,5$ & $2,3-5,9$ & $1,0-27,0$ & $1,0-8,3$ \\
\hline
\end{tabular}

mempengaruhi fotosintesis, laju respirasi, reproduksi maupun pertumbuhan. Kisaran temperatur yang baik bagi pertumbuhan lamun, yakni $28-30^{\circ} \mathrm{C}$ dan untuk proses fotosintesis temperatur optimumnya yakni $35^{\circ} \mathrm{C}$.

Salinitas dan temperatur merupakan faktor pembatas yang normal tetapi temperatur tinggi dapat penting karena dalam salinitas yang mengakibatkan kerusakan bahkan kematian dari lamun. Temperatur yang tinggi pada wilayah perairan dangkal di lokasi penelitian terjadi pada saat air surut sehingga pada perairan yang dangkal wilayah tersebut yang terdedah atau tersingkap, sehingga temperaturnya pun meningkat secara drastis mencapai $41{ }^{\circ} \mathrm{C}$. Sehingga lamun pada perairan dangkal ini cenderung berukuran lebih kecil dibanding dengan di wilayah perairan yang agak dalam.

Berdasarkan hasil penelitian diperoleh bahwa intensitas cahaya pada lokasi praktek adalah 187379.0 lux. Hasil ini lebih rendah jika dibandingkan dengan intensitas cahaya di perairan desa Arakan 330668.9 lux (Mery, 2012),

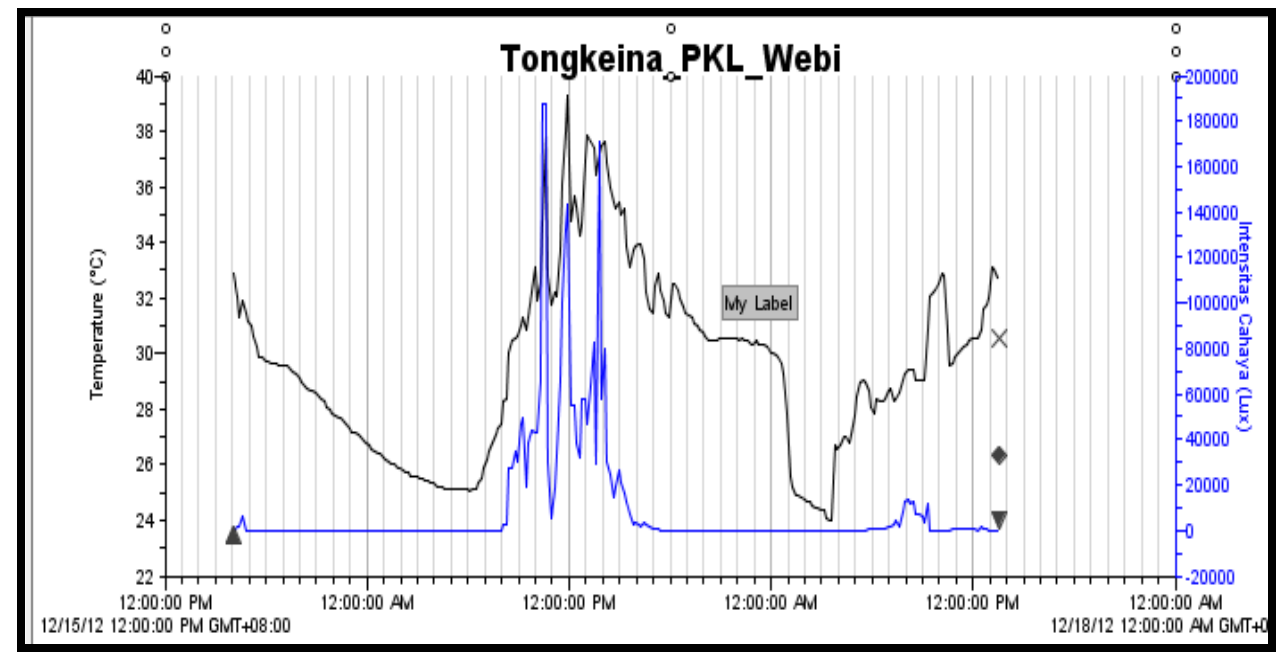

Gambar 6. Diagram hasil Pengukuran Temperature dan Intensitas Cahaya. 
sehingga dapat dikatakan penetrasi cahaya pada perairan di Tongkeina jauh lebih rendah. Tingginya proses sedimentasi yang mempengaruhi kecerahan merupakan salah satu akibat intensitas cahaya pada lokasi ini menjadi relatif rendah yang akan berdampak pada aktifitas fotosintesis dari tumbuhan laut termasuk lamun.

\section{KESIMPULAN}

Dari penelitian yang dilakukan ini, dapat disimpulkan bahwa:

1. Keadaan Ekosistem Padang Lamun di Perairan Kelurahan Tongkeina kecamatan Bunaken tergolong pada tipe campuran

(multispesific bed), dengan ditemukannya 4 spesies lamun antara lain Halophila ovalis, Thallasia hemprichii, Enhalus acoroides dan Syringodium isoetifolium.

2. Variasi morfometrik yang diukur antara lain panjang daun untuk $H$. ovalis berkisar $0,3-2,7 \mathrm{~cm}, T$. hemprichii $0,5-15,5 \mathrm{~cm}, E$. acoroides $2,0-54,3 \mathrm{~cm}, S$. isoetifolium $0,5-18,0 \mathrm{~cm}$; lebar daun untuk $H$. ovalis berkisar $0,2-$ $1,6 \mathrm{~cm}, T$. hemprichii $0,3-1,1 \mathrm{~cm}$, E. acoroides $0,6-1,5 \mathrm{~cm}, S$. isoetifolium $0,1-0,2 \mathrm{~cm}$; panjang batang pada $H$. ovalis berkisar $0,1-$ $4,1 \mathrm{~cm}, T$. hemprichii $3,0-8,6 \mathrm{~cm}$, E. acoroides $2,3-5,9 \mathrm{~cm}, S$. isoetifolium 1,0 - 5,0 cm; panjang akar pada $H$. ovalis berkisar $0,2-$ $5,3 \mathrm{~cm}, T$. hemprichii $0,3-15,0 \mathrm{~cm}$, E. acoroides $1,0-27,0 \mathrm{~cm}, S$. isoetifolium $0,8-6,4 \mathrm{~cm}$; selanjutnya panjang rhizoma pada $H$. ovalis berkisar 0,2-3,2 cm, T. hemprichii $0,8-6,0 \mathrm{~cm}, E$. acoroides $1,0-8,3$ $\mathrm{cm}, S$. isoetifolium $0,4-9,0 \mathrm{~cm}$.

3. Pengukuran kualitas perairan diperoleh; temperaturnya berkisar 23
- $39{ }^{\circ} \mathrm{C}$ (rata-rata $29{ }^{\circ} \mathrm{C}$ ) dengan intensitas cahaya tertinggi $187,379.0$ lux serta salinitas $30-33 \%$.

\section{DAFTAR PUSTAKA}

Calumpong, H. P dan E. G. Menes. 1997. Field Guide to the Common Mangroves, Seagrasses and Algae of the Philippines. Inc. Makati City, Philippines. p 197.

Dahuri, R., J. Rais., S.P Ginting dan M.J. Sitepu. 2003. Pengelolaan Sumber Daya Wilayah Pesisir dan Lautan Secara Terpadu. Djambatan. Jakarta. 328 hal.

Koch, E. W dan J. J. Verduin. 2001. Measurements of Physical Parameters in Seagrass Habitats: F. T. Short and R. Coles (Eds.). Elsevier Science B. V. Amsterdam. pp $325-344$.

Kordi K. M. G. H. 2011. Ekosistem Lamun (Seagrass). Penerbit Rineka Cipta ; Jakarta. 191 hal.

Kuo, J dan C. den Hartog. 2001. Seagrass Taxonomy and Identification Key dalam Global Seagrass Research Methods : F. T. Short and R. Coles (Eds.). Elsevier Science B. V. Amsterdam. pp 31 38.

Menez, E. G., R. C. Phillips dan H. P. Calumpong. 1983. Seagrasses from the Philippines. Smithsonian Institution Press, City of Washington. p 40.

Nybakken, J. 1992. Biologi Laut : Suatu Pendekatan Ekologis. PT Gramedia Pustakan Utama. Jakarta. 459 hal. 
Short, F. T., R. G. Coles dan C. P. Martini. 2001. Global Seagrass Distribution. dalam Global Seagrass Research Methods : F. T. Short and R. Coles (Eds.). Elsevier Science B. V. Amsterdam. pp 1 30.

Wagey, B.T. 2011. Morphological and Genetic Analysis of Seagrasses Halodule uninervis (Forsskål) Ascherson and $\underline{H}$. pinifolia (Miki) den Hartog in the Central Visayas, Philippines. Disertation Doctor, Siliman University Dumaguete City. p 103.

Waycott, M., Kathryn McMahon, Jane Mellors, Ainsley Calladine dan Diana Kleine. 2004. A Guide to : Tropical Seagrasses of the IndoWest Pacific. James Cook University. Australia. p 72. 